\title{
Realidad virtual, mímesis y simulación
}

\author{
Wenceslao CASTAÑARES*
}

Propuesto: 10 de marzo de 2011

Evaluado: 15 de mayo de 2011

Aceptado: 20 de mayo de 2011

(Abstracts y palabras clave al final del texto)

\section{REALIDAD VIRTUAL Y EXPERIENCIA}

En un número anterior de esta misma revista ${ }^{1}$ abordábamos el problema del cambio de régimen experiencial propiciado por la proliferación hipertrófica de las imágenes de las nuevas tecnologías. Nuestra reflexión pivotaba entonces en torno a dos conceptos que ahora hemos de volver a recuperar, los de realidad virtual y experiencia. En cierto sentido lo que ahora diremos viene a completar aspectos no abordados suficientemente en aquella ocasión con la intención de analizar críticamente algunas afirmaciones frecuentes en torno a esas cuestiones y de inspeccionar la situación presente con el arriesgado propósito de anticipar, más que lo que será, lo que no será el futuro, a pesar del éxito de ciertas profecías.

Respecto al primero de los dos conceptos comentábamos entonces la ambigüedad del término "virtual". En el lenguaje coloquial se ha convertido en un término-saco que se usa para aludir tanto a todo lo que de algún modo tenga algo que ver con las tecnologías digitales como para aquello que no se considera real, ya porque se trate de algún ente de ficción o de alguna realidad que no se considera plenamente realizada. En el contexto filosófico y científico, la "virtualidad" ha sido objeto de múltiples reflexiones que no pueden obviar, no sólo una historia que nos remite a su uso por los romanos, por la escolástica y la filosofía posterior ${ }^{2}$, sino por la óptica (imagen virtual) o la mecánica cuántica (partículas virtuales), lo que no contribuye precisamente a una definición lo suficientemente precisa. La filosofía de finales del siglo XX no puede obviar tampoco las reflexiones de G. Deleuze (2002) que han contribuido de forma decisiva a precisar el concepto de "virtual" al oponerlo no a lo real, como tantas veces se hace, sino a actual. Este cambio de perspectiva ha permitido

\footnotetext{
Universidad Complutense de Madrid

1 "Cultura visual y crisis de la experiencia". CIC 12, 207:29-48.

2 Para una historia del término desde la antigüedad romana hasta la escolástica, véase Biosca (2009). Del tratamiento filosófico y científico se ocupan Duque, Hidalgo, Pérez Herranz y otros en Eikasía 24 (2009).
} 
desatascar la reflexión, pero no ha acabado con la confusión reinante, a nuestro entender, por dos razones fundamentales. En primer lugar, porque la extensión del concepto no le permite "definir" aquel tipo de realidades a las que con más frecuencia se vincula: las representaciones producidas por las tecnologías digitales. Tan "virtual" es, como reconoce por ejemplo P. Lévy, un texto lingüístico como una fotografía en la pantalla de un ordenador o las imágenes de una consola para videojuegos. Que el uso coloquial lo utilice de forma casi inevitable para referirse a imágenes como las aludidas y no, por ejemplo, al texto de una novela, no nos ayuda nada a aclarar la cuestión, pero esto es algo que no podemos permitir que arruine nuestros análisis. En segundo lugar porque la reflexión filosófica insiste en considerar lo virtual como un problema eminentemente ontológico (una forma de ser) y porque privilegia especulaciones que prescinden de la experiencia inmediata de las tecnologías actuales.

Para huir de ese tipo de consideraciones, nosotros empezábamos por poner entre paréntesis esas perspectivas para referirnos, no a lo virtual en general, sino a la "realidad virtual" tal como fue entendida por aquello que empezaron a usar la expresión en el contexto de las nuevas tecnologías digitales en la década de los años ochenta. Esta reducción de la problemática nos permite concretar de forma bastante precisa a qué nos estamos refiriendo. Ya habrá tiempo, posteriormente, de generalizar las conclusiones. Como veremos esta reducción nos permitirá descentrar la reflexión para desviar nuestra mirada hacia aspectos frecuentemente ausentes de la perspectiva filosófica.

La expresión "realidad virtual" (una expresión que hoy podemos considerar poco afortunada por lo que acabamos de decir) se impuso tras algunas discusiones en el contexto de la tecnología. Las discusiones entre tecnólogos como J. Lanier, T. Nelson, M. Krueger o J. Walker no les desviaron de la cuestión central. Lo que estaba en juego era un problema práctico: encontrar formas de relación más "naturales" y "humanas" entre la interfaz y su usuario. Para conseguirlo se pensó en una tecnología que permitiera la percepción de un "mundo" diferente del "mundo físico". Para ello empezó a experimentarse una tecnología protésica (cascos, gafas, guantes) que permitía entrar en contacto con un "mundo virtual", que no era un mundo subjetivo o simplemente imaginado, sino un mundo que, aunque representado, podía ser percibido de modo semejante a como percibimos el mundo físico (Lanier 1988). Ted Nelson apunta otro aspecto de lo que se empieza a llamar realidad virtual que terminará también por ser muy relevante. Como en el caso de Lanier, se trata de lograr una relación interactiva con el sistema de la máquina, de tal manera que el objetivo es la creación de "un entorno mental" en el que se producen unos efectos semejantes a los que produce la realidad. En definitiva, lo que importaba era la "apariencia", "lo que parece ser" y sus efectos, que debían ser semejantes a los producidos por los objetos en el mundo de la vida cotidiana.

Este cambio de perspectiva nos permitía a nosotros vincular el problema de la "realidad virtual" al problema de la experiencia, otro concepto problemático que necesitaba ser aclarado. Aunque compartíamos algunas de las consideraciones de W. Benjamin entorno a la cuestión, no las seguíamos hasta el final, como tampoco podíamos aceptar las consecuencias que autores como G. Agamben sacaban de ellas. Dos eran las razones fundamentales que aducíamos. En primer lugar que las consi- 
deraciones de Agamben conducían a una noción de experiencia que negaba incluso su propia posibilidad. En segundo lugar, poníamos de manifiesto que si se renuncia a la experiencia resulta imposible explicar lo que consideramos un elemento fundamental de la forma de ser humana: su historicidad. Frente a ese planteamiento nosotros consideramos, como Benjamin, que la experiencia no puede reducirse ni a la mera experiencia sensible ni mucho menos, al "experimento" científico. Pero huíamos también de lo que podría considerarse una actitud radicalmente opuesta: la experiencia no puede reducirse tampoco a una red de relaciones discursivas. La experiencia implica apertura a lo otro, a esa realidad (la del objeto, la de los otros sujetos) que se presenta como problemática, incluso como "peligrosa", o "aventurera", puesto que continuamente está expuesta a lo inesperado. Esta apertura no niega sin embargo su naturaleza discursiva. No hay experiencia sin lenguaje y comunicación, lo que niega tanto la posibilidad de una experiencia sin sujeto como una experiencia meramente subjetiva. No hay pues una experiencia "pura", "inefable" (como quería Agamben), pero la impureza de esta otra experiencia es aquello mismo que la hace posible. Finalmente esta experiencia no puede ser concebida al margen de ciertas condiciones. Por supuesto, las del espacio y el tiempo, que si bien no son trascendentales y a priori, no dejan de establecer condiciones de las posibilidades y los límites de la experiencia. Estas condiciones hacen de la experiencia un fenómeno histórico y cultural, sometido por tanto al cambio y a las relaciones de poder que la existencia comunitaria lleva implícitas. Y es por esto por lo que experiencia necesariamente está expuesta a "crisis", sometida a juicio, cada vez que cambian las condiciones que la hacen posible. Esta crisis de la experiencia es (como diría Ortega y Benjamin fue capaz de ver) el "tema de nuestro tiempo".

Partiendo de estos supuestos trataremos de profundizar a continuación en las causas por las que la experiencia de los hombres del siglo XXI (y no el concepto mismo) "entra en crisis" y las consecuencias que esta crisis tiene para nuestra concepción del mundo y de nosotros mismos, una problemática que en nuestro anterior artículo apenas quedaba esbozada. Una de las causas más importantes de estos cambios en la construcción de la experiencia lo constituyen los discursos que hacen posible las nuevas tecnologías de la información y la comunicación. Y, puesto que no podemos abordar esta compleja problemática en su totalidad, hemos decidido centrarnos en una de sus expresiones, aparentemente al menos, más revolucionarias: la "realidad virtual". Considerada como una nueva forma de representación, la realidad virtual parece ser el resultado de un proceso evolutivo, hace largo tiempo iniciado, pero al que aún se le augura un largo recorrido. Este proceso consiste en la sustitución de la realidad por sus representaciones. Para ese proceso se ha imaginado un final provisional que consistiría ni más ni menos que en la posible reducción del hombre a sus manifestaciones cerebrales, y, en definitiva, en la posibilidad de prescindir del cuerpo mismo. El hombre no sería más que mente y ésta, información pura susceptible de ser digitalizada y descargada en una máquina. Lejos de tales especulaciones, nosotros nos limitaremos al análisis de la realidad virtual tal como la hace posible la tecnología actualmente disponible. A partir del análisis de lo que es hoy la realidad virtual, trataremos de vislumbrar cuáles son sus posibilidades y sus límites en su intento de representar y, en algún sentido, sustituir la realidad. 


\section{LA REALIDAD VIRTUAL Y SUS MODALIDADES}

Si tuviéramos que sintetizar lo anteriormente expuesto podríamos decir que, de forma tentativa, aquí llamaremos "realidad virtual" a aquel tipo de representaciones generadas digitalmente que pretenden producir el mismo tipo de efectos perceptivos que los objetos sensibles de la realidad física de la vida cotidiana y que reacciona ante la acción del hombre de forma semejante a como lo hace esa realidad. Esta restricción terminológica y conceptual afecta, pues, a dos aspectos que consideramos fundamentales. La primera de ellas es para nosotros la más importante porque es la que nos permite ese descentramiento de la reflexión filosófica al que antes hemos aludido. La "realidad virtual" no se opone a la "realidad física" de los objetos que nos rodean en la vida cotidiana. La "realidad virtual" es una "representación". En términos coloquiales que más adelante tendremos que precisar, la "realidad virtual" es, básicamente, una imagen. Desde este punto de vista, de establecerse alguna oposición, esta sería la que cabe establecer entre la "representación" y "lo representado". La primera consecuencia de esta consideración es que, aunque no puedan (ni deban) obviarse los problemas ontológicos que la realidad virtual pueda plantear, los problemas más inmediatos (sobre todo en relación al problema que nosotros nos plantearemos que es el de la experiencia) son de naturaleza semiótica. Consecuentemente, el tipo de problemas que nos plantearemos tienen que ver con la naturaleza de esas representaciones, con aquello que representan (sus "objetos" en el sentido que da C.S. Peirce a esta expresión) y con el tipo de efectos que producen esas representaciones.

La segunda restricción afecta en algún sentido a la oposición que estableciera Deleuze entre virtual y actual. Sin duda alguna, "la realidad virtual" es "virtual" en el sentido en que este concepto se opone a "actual"; pero no más que lo es el texto de Madame Bovary o la imagen digital de la esfera terrestre que tengo en la pantalla de mi ordenador. Como decíamos más arriba, en este sentido, el adjetivo "virtual" no es definitorio, no marca los límites del objeto de nuestra reflexión. Por lo demás, nosotros llamaremos "realidad virtual" a un tipo de representaciones que son producidas por las tecnologías digitales, pero no a cualquiera de esas representaciones, como tantas veces se hace.

No obstante hay que aclarar de forma inmediata que este tipo de representaciones contiene a su vez varios subtipos o modalidades. Como explicábamos más arriba, el objetivo de los tecnólogos que inventaron la expresión consistía en el desarrollo de tecnologías que fueran capaces de producir imágenes que, tanto en su apariencia como, sobre todo, en sus efectos fueran semejantes a los objetos de nuestra percepción. La idea tal como fue concebida en sus inicios era muy atractiva, pero los dispositivos técnicos que se idearon no dejaban de tener serios inconvenientes. Lo que se estaba gestando era una idea revolucionaria a la que la tecnología tendría que ir dando forma y buscando salidas diferentes. En ese proceso de búsqueda, el desarrollo de la tecnología ha ido lidiando con dos tipos de problemas. El primero de ellos era un problema técnico: las limitaciones de los sistemas de computación disponible y, en todo caso, su vinculación con dispositivos de hardware demasiado complejos que condicionaban la movilidad de sus usuarios y, en definitiva, su uso. 
El segundo era económico: el coste de tales dispositivos dificultaba una comercialización masiva que les hiciera rentables. Consecuentemente, la tecnología de la "realidad virtual" ha evolucionado en dos sentidos diferentes. Ciertos dispositivos mantienen el objetivo ideal de los comienzos: aislar a los usuarios del contexto físico circundante y bombardearlos con una serie de estímulos producidos por imágenes que el cerebro interpreta de forma muy semejante a como lo hace en presencia del objeto representado. Es el caso de los simuladores de vuelo de sofisticados aviones, de conducción de automóviles en diversos circuitos, de aplicaciones médicas diversas o la de "cuevas" (CAVES) en cuyas paredes se proyectan imágenes que, contempladas con gafas especiales, producen efectos visuales, auditivos y hápticos (fundamentalmente de movimiento y equilibrio) muy semejantes a los que se producirían en la realidad física. A este tipo de realidad virtual se la ha denominado "inmersiva". En un sentido estricto, la realidad virtual vendría definida, pues, como ha propuesto M. Heim (1993:7), por “tres i”: inmersiva, interactiva, (información) intensiva.

Pero tales dispositivos técnicos no son de uso masivo ni se prevé que puedan serlo en un futuro inmediato; de ahí que se hayan buscado otras aplicaciones que no aíslan totalmente al individuo (no son "inmersivas" en sentido estricto) pero producen efectos sensibles visuales y de movimiento muy semejantes a lo que producen los objetos reales. Tal es el caso de la denominado realidad aumentada (augmented reality), la realidad mixta (mixed reality) y todas aquellos que caen bajo el concepto de representación interactiva $3 \mathrm{D}^{3}$. Este tipo de representaciones comparten con la realidad virtual intensiva su carácter interactivo y algunos efectos de realidad similares a los que producen los objetos. De alguna manera podría considerarse que se trata de una realidad virtual "degenerada", que conserva en parte algunas de las características de la realidad virtual inmersiva, pero resulta, en el momento tecnológico actual, mucho más manejable y menos costosa. Aunque nosotros nos referiremos fundamentalmente a la realidad virtual inmersiva, no cabe duda de que muchas de nuestras reflexiones son aplicables a este otro tipo de representaciones no inmersivas.

\section{REPRESENTACIÓN, MÍMESIS Y SIMULACIÓN}

La perspectiva desde la que abordamos la problemática que plantea la realidad virtual exige la revisión de otros conceptos discutidos, polisémicos, que sin embargo resultan claves en nuestra reflexión. Especialmente los de representación, mímesis y simulación. Si bien se trata de expresiones que han sido interpretadas de forma diversa y polémica, nosotros los usaremos de acuerdo a ciertas tradiciones que, aunque sea de forma sintética, pasamos a explicar.

Representación es para nosotros un concepto semiótico que vamos a entender de forma muy próxima a como ha sido interpretado por la tradición escolástica que fue

3 La proximidad entre estos dos tipos de "realidad virtual", inmersiva y no inmersiva, ha llevado a que las líneas de investigación tecnológica se desarrollen conjuntamente, como pone de manifiesto, por ejemplo, la L'Association française de Réalité Virtuelle, Augmentée, Mixte et d'Interaction 3D (AFRV) (http://www.afrv.fr. [Consultada 8/05/2011]). Algo semejante ocurre en España con el Centro de Domótica Integral de la Universidad Politécnica de Madrid (http://www.cedint.upm.es/es [Consultada 27/04/2011]) 
recuperada, ya a las puertas del siglo XX, por el filósofo y científico americano C.S. Peirce. Si bien es cierto que no todo tipo de signo puede ser considerado una representación (los signos indiciales, si es que existen signos indiciales puros, escaparían de esa consideración), no cabe duda de que la mayor parte de los signos (aquellos que posean elementos icónicos y simbólicos especialmente) pueden ser considerados representaciones. Es característico de estos signos el "estar en lugar de algo" (stat pro aliquo, stands for something), que en esa tradición que acabamos de mencionar, y especialmente en la semiótica de Peirce, es llamado su objeto, por más que suponga interpretar este término en un sentido poco usual. Para evitar entrar en matizaciones teóricas que nos distraerían de nuestra meta, diremos simplemente que "objeto" es lo representado por un signo, sea cual sea su naturaleza ontológica. Así serán considerados "objetos", los seres representados en las esculturas de los frisos del Partenón a los que llamamos "centauros", la reina Isabel II representada en un retrato (bien sea un cuadro o una fotografía) o el Estado simbolizado por una bandera con los colores rojo y amarillo. Las imágenes digitales producidas sintéticamente u obtenidas por una cámara fotográfica, son sin duda representaciones en el sentido semiótico aludido.

Teniendo en cuenta estos prepuestos podemos decir que lo que hemos denominado "realidad virtual" es antes que nada, una imagen visual percibida como tridimensional y móvil, que puede estar reforzada por otras imágenes de carácter auditivo y háptico para acentuar la ilusión de que no se trata de representaciones sino de objetos. La naturaleza "visual" de esta imagen, podríamos decir que es "constitutiva", mientras que sus propiedades no visuales o bien son dependientes de su visualidad o bien son complementarias. De forma más concreta, como veremos más adelante, un componente fundamental de estas imágenes es el movimiento, pero como en cierto sentido ocurre en el cine, ese movimiento es un efecto de la naturaleza visual de la imagen. No ocurre lo mismo con los efectos auditivos que, de alguna manera podemos considerar como independientes de la visualidad. Podemos cerrar los ojos y seguiremos escuchando los sonidos. Ahora bien, suprimamos la imagen visual y en gran medida habrán desaparecido los efectos característicos de la realidad virtual, mientras que los efectos auditivos y hápticos (al menos algunos de ellos) pueden considerarse no totalmente pertinentes. Así por ejemplo, en las "cuevas" de proyección de la realidad digital pueden suprimirse los efectos táctiles para quedarse únicamente con los visuales, de movimiento (y por tanto de equilibrio) y sonoros. Si tenemos en cuenta estas consideraciones podemos decir que estamos ante una forma de representación que conserva elementos que ya poseían las imágenes fotográficas, del cine $\mathrm{y}$ de la televisión, pero que introducen otros que modifican las convenciones que han estado vigentes en la cultura occidental desde principios de la Edad Moderna, por ejemplo, las que afectan a la visión tridimensional o las relaciones de acción y reacción que coloquialmente llamamos "interactividad".

Contrariamente a lo que muchas veces se cree, la naturaleza semiótica de la realidad virtual, no determina el tipo de objetos que puede representar. La realidad virtual, como cualquier otro tipo de representación, puede representar objetos reales o de ficción. En términos más concretos, la realidad virtual puede representar un edificio no existente, incluso de improbable existencia, pero también un edificio real- 
mente existente, como una catedral determinada. Naturalmente, el origen de las imágenes es distinto en uno y otro caso. Mientras en el primero son productos infográfícos, en el segundo se trata de imágenes tomadas de la realidad por cámaras con tecnología 3D. No puede afirmarse, por tanto, que la realidad virtual sea autorreferencial o que cree mundos inexistentes sin vinculación con el mundo real. Antes al contrario, tiene una clara intencionalidad mimética que está expresada en su misma definición. La realidad virtual vuelve a plantear, una vez más, el complejo problema de la semejanza, por más que sea este un concepto que es necesario aclarar.

Cuando decimos que la realidad virtual tiene una clara intencionalidad mimética queremos decir que es una representación que tiene como objetivo, no sólo parecerse a su objeto (en el sentido semiótico del término), lo que haría de ella un icono, sino que quiere producir los mismos efectos que esos objetos. Es decir, su iconicidad no ha de ser entendida como una mera relación semántica (establecida entre el signo y su objeto) sino que extiende esa propiedad a la dimensión pragmática. Las imágenes más características de la realidad virtual encarnan de modo privilegiado la acción mimética tal como la concibió Aristóteles ${ }^{4}$, es decir, como aquella acción que consiste en decir "esto es aquello" (Poét., 1448b, 18). En cuanto representación, la realidad virtual no puede evitar que la diferenciemos de lo que representa, tanto en el orden conceptual como en el perceptivo; pero pretende llevar esa "afinidad" (Ret. 1371 b 12 -14) que Aristóteles encontraba entre los dos polos de la mímesis, hasta extremos que sin duda el filósofo no pudo imaginar.

Como el mismo Aristóteles aclara, decir de una representación que es mimética, no determina ni la naturaleza de los medios de la imitación, ni los objetos imitados, ni los modos de la imitación. Estas diferencias, que permitieron al Estagirita distinguir entre las diversas artes miméticas (Poét. 1447a 14-18) pueden servirnos a nosotros como un modo de distinguir las diversas formas que puede adquirir la realidad virtual. Dado que aquí no podemos abordar esta problemática en toda su dimensión, nos limitaremos a abordar algunas cuestiones relacionadas con los medios de la imitación y con los objetos imitados.

Generalmente tiende a pensarse que las imágenes de la realidad virtual son producidas sintéticamente y que éstas producen incluyo mayores efectos de realidad que las imágenes fotográficas y fílmicas. Un examen más detenido de la realidad tecnológica de la que disponemos pone de manifiesto que estas apreciaciones son bastante inexactas. En primer lugar hay que afirmar que, como hemos dicho más arriba, las imágenes en ocasiones tienen origen fotográfico $\mathrm{y}$, frecuentemente, se recurre también a la mezcla de imágenes fotográficas e imágenes sintéticas. Pero sea cual el origen de las imágenes, como ha observado Manovich (2005:254-255), la tecnología actual parece decidida a armonizar un doble objetivo: la simulación de

4 El concepto de mímesis adquiere en Aristóteles una complejidad que aquí no podemos analizar. No obstante el texto citado hay que interpretarlo en contexto de la Poética que, como es sabido, se ocupa de la mímesis en la tragedia. En ese contexto, la imitación es una representación teatral y el objeto de la imitación son las "acciones humanas". La mímesis va, pues, más allá de lo que un examen superficial de las obras de otras artes miméticas como la pintura o la estatuaria pudiera dar a entender. Esa noción de mímesis incluye también la acción, lo que para nosotros resulta esencial. 
los códigos de la fotografía de cine tradicional y la simulación de las propiedades perceptivas de los objetos. El primero de ellos (profundidad de campo y desenfoque debido al movimiento, iluminación controlable) fue fácil; el segundo está resultando ser mucho más complejo. El resultado es un realismo bastante desigual. Si nos atenemos a los resultados, comparada con la imagen fotográfica, la imagen sintética es más nítida, sus formas más geométricas, sus colores más vivos, sus detalles (cuando puede reproducirlos) más visibles. En este sentido cabe decir que la tecnología digital en general tiene la pretensión de actuar como prótesis que supera los límites de la visión humana o de otros aparatos ópticos produciendo imágenes "demasiado reales" (Manovich 2000:267) o "hiperrealistas". Sin embargo, como ya sabemos gracias a la tradición cinematográfica (piénsese, por ejemplo, en el color), dichos efectos "hiperrealistas" son convenciones que producen "efectos de realidad" pero que, cuando se las examina detenidamente, son producidos por estímulos muy diferentes de las características de los objetos físicos tal como son percibidas en nuestra vida cotidiana. Pero frente a estos éxitos de la imagen sintética, en otros aspectos, los obstáculos siguen sin superarse. Así, por ejemplo, simular ciertos movimientos, particularmente los de la figura humana, está resultando un reto que no se acaba de lograr. La superación exitosa de los diversos problemas pasa, de momento, por soluciones distintas dependiendo de la funcionalidad de las imágenes. Mientras que en las tecnologías que tienen como objetivo una funcionalidad práctica (como es la de los simuladores), la imagen fotográfica sigue siendo de gran utilidad, en los videojuegos la imagen sintética, a veces muy esquemática, tiene una ventaja evidente: la economía de medios. Esta esquematización o simplificación de la imagen no ha sido óbice para su aceptación, aunque la tendencia sea la de aproximarse lo más posible a la imagen fotográfica, que sigue siendo considerada como más realista.

El cine, por su parte, se ha aprovechado de estas posibilidades, utilizando ambos tipos de imágenes. La imagen exclusivamente sintética ha revolucionado el mundo del "cine animado", mientras que la filmación digital ha permitido la incorporación de la imagen sintética a filmaciones fotográficas. Esta última solución es especialmente elocuente, no sólo porque ha obligado a hacer compatibles dos formas de representación de naturaleza distinta, sino porque permite contrastar de nuevo un principio que parece operar cuando se introducen nuevas tecnologías: en toda innovación tecnológica hay ganancias y pérdidas. Sin intentar ahora hacer un balance de lo que se gana y lo que se pierde, hay una pérdida que resulta evidente: la de la indicialidad de la imagen fotográfica o cinematográfica. La iconización del índice (Machado 2009:179), es una tendencia inevitable no sólo en la imagen de la realidad virtual sino en las representaciones más características de los nuevos medios. Paradójicamente, como ha señalado Manovich (2005:239 ss.) esta pérdida no contradice la tendencia hacia lo figurativo, incluso al realismo fotográfico, ni muchos menos ha afectado a un imaginario que sigue siendo cinematográfico. Simplemente introduce otras convenciones en la representación que dan la impresión de ser más realistas aunque propiamente no lo sean.

Pero la imagen de la realidad virtual, desde el momento mismo de su concepción, tiene una pretensión de aproximación a la realidad que va más allá de la mímesis tal como ha sido tradicionalmente entendida por la pintura y la fotografía. No se 
trata simplemente de que la imagen se asemeje a los objetos representados, sino que pretende ocupar su lugar, ser percibida como son percibidos sus objetos. En otros términos, su objetivo consiste en convertirse en un simulacro.

Al igual que ha ocurrido con la mímesis, el simulacro ha sido entendido también de muy diversas maneras ${ }^{5}$. Más allá de que sea un concepto que tiene una historia que nos remite de nuevo al pensamiento griego ${ }^{6}$, difícilmente se puede eludir hoy el sentido en que ha sido utilizado en nuestros días por J. Baudrillard. Como ya hemos comentado en otro lugar (Castañares 2010:75-76), nosotros no entendemos la expresión en un sentido tan amplio como el autor francés. Coincidimos con él en dos aspectos básicos. Detrás del simulacro existe una intencionalidad de fingimiento, por más que este fingimiento sea de una especie peculiar. El fingimiento de la simulación es muy diferente, como sostiene Baudrillard (1984:12), del fingimiento del disimulo. "Disimular", dice el DRAE, es "encubrir con astucia la intención"; mientras "simular" es "representar algo, fingiendo o imitando lo que no es". Disimular, dice Baudrillard, es fingir no tener lo que se tiene, mientras que simular es fingir tener lo que no se tiene. La primera acción remite a una presencia; la segunda, a una ausencia. Y es esa ausencia la que hace del simulacro una representación, porque siempre remite a algo que no está presente, aunque lo ignore aquel a quien se presenta. Ahora bien, un examen detenido de los distintos tipos de simulacros pondría de manifiesto, primero, que el fingimiento es más o menos sincero, pero también que no puede confundirse la "ausencia" de algo con su "inexistencia", como da a entender el Diccionario. En ocasiones (como ocurre con los decorados del cine o del teatro) el simulacro es una representación que no es que no tenga objeto, sino más bien que pretende pasar por él. De esta manera el simulacro lleva al signo a su completa realización: ocupar el lugar de su objeto. Posiblemente Baudrillard tenga razón también cuando afirma que nuestra época, la edad posmoderna, hace posible el triunfo del simulacro. Pero habría que señalar que estamos ante una situación paradójica. En el pasado, los simulacros (estamos pensando sobre todo en aquellos que son simulacros de cosas y no tanto simulacros de acciones), para pasar por su objeto, tenían que adquirir una cierta materialidad. La tendencia de nuestra época es justamente la contraria: convertir lo material en información que pueda circular por las redes del ciberespacio, lo que indudablemente la confiere una cierta inmaterialidad.

La realidad virtual encarna mejor que ningún otro tipo de representación esta paradoja: pasar por su objeto, tratar de ser en definitiva un simulacro y, al mismo

\footnotetext{
5 En sentido estricto, "simulacro" es un concepto pre-semiótico que se utiliza para referirse a representaciones de naturaleza muy diversa. Así por ejemplo, un edificio en cartón piedra como los que utiliza el cine o el teatro puede ser considerado un simulacro. Pero también se denominan así los ensayos de evacuación de un edificio en el que se ha declarado un incendio. A pesar de sus diferencias, para nosotros, en ambos casos, estamos ante representaciones, en el sentido más arriba definido.

6 Platón, en el Sofista (235d, ss.), establece la distinción entre dos técnicas o procedimientos miméticos. Una de ellas es la producción de imágenes (eikastiké), que en algunas traducciones se ha denominado "figurativa" porque produce copias o imágenes (eikona). La segunda consiste en la producción de apariencias (phantasma), por lo que se la ha denominado, "simulativa" (phantastiké). No resulta fácil traducir los términos griegos a las lenguas románicas, en las que son más frecuentes las expresiones de origen latino como "imagen", "figura", "simulacro" y "simulación"; pero hay, sin duda, un cierto paralelismo entre los conceptos platónicos y los que venimos utilizando.
} 
tiempo, información digitalizada. Está por ver si logra resolver esa contradicción. De momento no lo ha conseguido. Para conseguirlo tendrá que superar obstáculos muy serios. El primero de ellos, el que ha sido siempre el gran obstáculo de la imagen tal como la concibió la pintura, la fotografía y el cine: la bidimensionalidad. En los nuevos medios, la solución se ha conseguido actuando en dos frentes: sobre la representación misma y sobre la tecnología de la visión. La realidad virtual, tanto la inmersiva como la no inmersiva, se ha enfrentado a ese problema de manera en parte distinta pero en definitiva con un mismo objetivo: crear la ilusión de un espacio tridimensional que aloja objetos tridimensionales. La primera recurrió inicialmente a un casco que permitía la visión tridimensional en unas pantallas binoculares que no recogían sin embargo el movimiento de la cabeza y el cuerpo del usuario. Posteriormente, mediante las "cuevas"7 de cinco paredes convertidas en pantallas que sumergen al usuario en un mar de imágenes y de unas gafas binoculares que son las que permiten percibir esas imágenes como si fueran tridimensionales. La tecnología no inmersiva se limita al uso de los gafas para la percepción de las imágenes que se proyectan en una pantalla. Ya sabemos que los diversos tipos de procedimientos tienen definidos sus propios destinatarios y objetivos. Las cuevas y los simuladores utilizados sobre todo con fines militares, médicos o deportivos, son complejos y costosos. Tienen unos destinatarios que constituyen una minoría pero que están respaldados por instituciones que pueden soportar el coste de una tecnología compleja y cara. Sin duda, aún tienen un cierto recorrido en su desarrollo. Pero este vendrá definido por su eficiencia. Después vendrán, como ha sucedido hasta ahora, sus aplicaciones al ocio. Pero es presumible que no podrán ofrecer todas las posibilidades de las aplicaciones prácticas. Los dispositivos menos complejos de la realidad virtual no inmersiva tienen como objetivo un consumo más masivo con aplicaciones que, por el momento, son principalmente de carácter didáctico o de entretenimiento. Es de suponer que su desarrollo dependerá de las limitaciones económicas, pero sin duda está pensado para un uso masivo.

En cualquier caso, el cine y la televisión 3D están preparando ese consumo. Después de algunas dudas (que en el cine han sido especialmente elocuentes) los responsables de la industria y los creadores parecen haberse decidido a producir películas y programas televisivos de difusión masiva. El impacto ha sido desigual, pero es posible que, aunque a medio plazo no supongan la desaparición de sus inmediatos antecedentes, vayan generalizándose. Basta haber visto una película como Avatar (J. Cameron 2009) o Alicia en el País de las maravillas (T. Burton 2010) para darse cuenta de la importancia que sigue teniendo la perspectiva, como también la eficacia en la solución de los retos que suponía la combinación de imágenes cinematográficas y sintéticas. Pero al mismo tiempo, hacen evidente las limitaciones de todo tipo. Aún estamos lejos de conseguir esa homogeneidad de las imágenes que se

\footnotetext{
7 La expresión inglesa "cave" se utiliza para designar el artilugio tecnológico que describimos y que podría considerarse una especie de cueva. Pero, al mismos tiempo CAVE son las siglas de Cave Automatic Virtual Environemet que es el nombre que se dio al dispositivo de producción de realidad virtual creado por la Universidad de Illinois en colaboración con el National Center for Supercomputing Applications. Como en otras ocasiones la marca registrada de un producto se convierte en una categoría genérica.
} 
aprecia en aquellos casos en que sólo se utilizan imágenes fotográficas o imágenes sintéticas y que, en el contexto de las convenciones actuales, dan esa impresión de "realismo" o "hiperrealismo" característico de cada una de una de ellas.

La imagen virtual ha heredado del cine la imagen-movimiento (Deleuze 1984) pero modificándolo de forma sustancial en varios aspectos. El espacio tridimensional de la realidad virtual puede ser explorado de una forma hasta ahora inédita, para la que el término más apropiado es el de "inmersión", expresión que, si bien sigue siendo metafórica, lo es de manera distinta a como ha sido utilizada en otros contextos ${ }^{8}$. En cualquiera de sus usos, "inmersión" es un término que dirige nuestra mirada hacia un elemento de naturaleza líquida y a la forma más adecuada de desplazarse por él. De ahí también el éxito del término "navegación" para referirse a esta forma de desplazamiento, por más que este último término pueda adquirir un sentido más restringido. En la navegación oceánica no existen caminos (no por casualidad, para los griegos, el mar es la aporía, el lugar donde no hay poros [camino]), lo que en definitiva quiere decir que, en principio, puede navegarse (o ir a la deriva) en cualquier dirección. Mientras la técnica lo impidió, la navegación fue "superficial" (en el sentido literal del término) y determinada. Pero con el tiempo el hombre ha sido capaz de responder a la llamada de las profundidades submarinas. Como el espacio navegable, el espacio de la realidad virtual puede explorarse en todas direcciones y no sólo en los ejes vertical y horizontal característicos de la visión y el movimiento humanos. Probablemente sea este uno de los aspectos más novedosos de la experiencia que proporciona la realidad virtual porque, también en este sentido sus representaciones son "más reales que la realidad". Ninguna otra simulación ha logrado la sensación de libertad que permite el "vuelo" por cualquiera lugar de ese espacio tridimensional. Los objetos se acercan o se alejan a voluntad y sus detalles pueden ser observados desde todas las perspectivas con una minuciosidad sorprendente. Esta sensación de movimiento va acompañada de otra sensación que la hace aún más verosímil: la del equilibrio y el vértigo. La velocidad o la sensación de estar suspendidos en el espacio provocan en no pocos sujetos un vértigo difícilmente soportable. La sensación de libertad proviene de la superación de otra de las limitaciones de la imagen-movimiento del cine. El movimiento de la realidad virtual ya no está determinado por un mecanismo autónomo de arrastre, como ocurría en el cinematógrafo. Ahora es el propio sujeto el que controla el dispositivo y de él depende la velocidad y la dirección del movimiento. Puede decirse, pues, sin exageración que la sensación de movimiento resulta mucho más realista que la materialidad de los objetos, es decir de su tridimensionalidad y, desde luego, que su colorido (tan convencional) o su textura.

La textura de los objetos reclama una prueba definitiva: la del tacto. Este ha sido también un viejo sueño de los simulacros. A pesar del predicamento de la vista como criterio de realidad ("si no lo veo no lo creo") lo cierto es que, como pone de manifiesto el conocido y tantas veces representado episodio evangélico (Juan 20, 24 ss.),

8 El concepto de inmersión se ha utilizado también en contextos literarios para explicar la forma en que interpretamos los mundos de ficción (Schaeffer 2002). Es claro que en este nuevo contexto tiene un sentido diferente, menos metafórico, si es que puede hablarse en estos términos. 
es el tacto el que se reserva la prueba definitiva. El tacto es el antídoto contra la alucinación. No es de extrañar, por tanto, que los tecnólogos que concibieron la realidad virtual lo consideraran también como un factor clave de su realismo. La solución tecnológica pasaba por calzarse unos guantes que simularan las sensaciones táctiles, pero lo cierto es que parece un tanto olvidado. De hecho en las "cuevas" de realidad virtual inmersiva no se considera un factor determinante9.

Sin embargo, la tecnología digital ha encontrado formas de interacción en las que el movimiento del sujeto (y no sólo de las imágenes) y el tacto permiten modalidades de interacción que es muy posible que la realidad virtual pueda incorporar en un futuro no muy lejano. Los artefactos para la captación de los movimientos de los sujetos y la consiguiente reacción de las imágenes representadas en una pantalla están ya incorporados a tecnologías de difusión masiva. Y lo mismo puede decirse del tacto, por más que sea el tacto de la pantalla y no el de los objetos mismos. El tacto de la pantalla y el movimiento confieren a la interacción entre el sujeto y la máquina un realismo también novedoso. Incorporar estas posibilidades a la realidad virtual inmersiva es cuestión de "intensidad" de la información y por tanto, de avances tecnológicos que son posibles a corto o medio plazo.

En el momento en que la realidad virtual incorpore estas posibilidades que incluyen tecnologías que ya son de uso masivo, logrará experiencias insólitas si las comparamos con formas de representación anteriores. Dado que el espacio representado de la realidad virtual es al mismo tiempo una representación (nos remite a otro espacio), posee todas las características de este tipo de representaciones y puede ser sometido a las mismas operaciones a las que se somete un texto o una imagen digital. Consecuentemente, puede ser utilizado como interfaz, es decir, como medio de control. De esta manera, el espacio actualizado en la pantalla puede estar hipervinculado y permitirnos el acceso a otros espacios representados, lo que le da una nueva "profundidad". Este hecho pone de manifiesto otra característica no tan manifiesta pero de la que los usuarios tienen amplia experiencia: el espacio está organizado en diversos niveles y por tanto, más que al espacio continuo y homogéneo sugerido por la metáfora de la inmersión y la navegación, se trata de un espacio fragmentado, discontinuo, y que más que un receptáculo en el que puede colocarse los objetos, está formado por una agregado de objetos. La navegación por este espacio se convierte entonces en un paseo por mundos discontinuos, al estilo del mundo en el que Alicia se interna después de haber traspasado el espejo (otro ideal mitológico de la tecnología).

Este fenómeno pone de manifiesto otra propiedad también insólita: los espacios representados por las computadoras, si no son más táctiles que visuales, tal como afirma Manovich (2005:324), al menos han convertido al tacto, junto al movimiento del usuario, en elementos fundamentales de la interactividad que reclaman. Este espacio representado reacciona al tacto y al movimiento del usuario, bien sea para descubrirle otras zonas espaciales que hasta entonces no eran percibidas, bien sea para modificar su apariencia o la de los objetos que mantiene agregados. En este sentido hay que subrayar que, de momento al menos, el tacto está siendo el procedimiento mediante el

9 Hemos de confesar que nosotros no hemos podido experimentar con ellos. 
cual se interactúa con el interfaz, mientras que la utilización de la voz como forma de interacción todavía se ve reducida a aplicaciones muy concretas.

Por último hay otro aspecto que no podemos obviar, pero al que sólo podemos aludir de pasada. El movimiento de las imágenes, su aparición en el espacio perceptivo del usuario, implica una concepción del tiempo y unos procedimientos para su representación que también están determinados en último término por la tecnología y por la naturaleza misma de la representación. Una vez superado el reto tecnológico de que el tiempo de la interfaz fuera lo que se ha dado en llamar el "tiempo real", es decir, el tiempo de reacción casi instantáneo o de breves segundos, el movimiento de la realidad virtual trata de someterlo a la voluntad del usuario. De esta manera, con relación al movimiento cinematográfico, la realidad virtual introduce otra novedad sobresaliente: el movimiento de la representación no está determinado de antemano; depende en gran medida de la acción del usuario. Estamos por tanto ante un nuevo elemento hiperrealista: el tiempo resultante es un tiempo subjetivo que puede ser detenido, acelerado o ralentizado a voluntad. La manipulación del tiempo de la representación no deja de tener consecuencias sobre el tiempo representado como ponen de manifiesto las nuevas formas de narración que las nuevas tecnologías están permitiendo ensayar.

A pesar de nuestros intentos, no es posible hacer una descripción, ni siquiera aproximada, de las posibilidades que hoy ofrecen las nuevas tecnologías y las que nos ofrecerán en el inmediato futuro. Hemos querido referirnos sólo a las que son más manifiestas en el actual desarrollo de la realidad virtual y, de forma muy tentativa, a otras que podrían incorporar en el futuro. Ahora bien, con los datos que poseemos podemos intentar evaluar el grado de consecución de las metas que proponían los tecnólogos cuando la concibieron. En esta evaluación aparecen problemas que, estrictamente, no son nuevos. Bien mirado, en el afán innovador que da lugar a la aparición de la realidad virtual late un impulso que ha desatado la imaginación del hombre desde tiempos inmemoriales. Si hacemos caso a leyendas que en la cultura occidental tienen notable antigüedad (a este propósito nos valen tanto el de la muchacha de Lesbos que pinta la silueta de su amado en la pared como la tan comentada competición entre Zeuxis y Parrasio), la finalidad ilusoria de la imagen visual ha sido una constante que se ha tratado de conseguir por medios diversos. Como antaño ocurriera con la pintura, la fotografía y el cine, la realidad virtual nos obliga a reconsiderar un problema ya clásico: el de las relaciones entre representación, ilusionismo y realismo ${ }^{10}$.

En su intento de hacerse pasar por lo que no son, las imágenes visuales de la realidad virtual podrían considerarse como simulacros muy semejantes a otros que las han precedido en el tiempo. Así, por ejemplo, podría concluirse, los efectos de realidad no son más que convenciones aceptadas por una sociedad en un momento determinado. La pintura, la fotografía y el cine, encontraron cada una las suyas. Sin embargo este

10 A este respecto, resultan muy ilustrativas las reflexiones de Bazin (1999:26) en torno a cómo las artes plásticas, la fotografía y el cine han tratado de satisfacer una doble aspiración del hombre. Una de carácter estético (expresión simbólica de realidades espirituales) y otra de carácter psicológico (reemplazar el mundo por su doble). La realidad virtual no es sino un hito más en este recorrido al que no se le ve fin. 
tipo de conclusiones resulta poco esclarecedora en cuanto que encubre algo que, sin embargo, es también bastante evidente: comparadas entre sí, unas imágenes visuales resultan más ilusorias que otras. Hay que preguntarse, pues, qué es lo que define a la realidad virtual o, lo que es lo mismo, qué tipo de simulación es capaz de producir. Ahora bien, dada esa pretensión explícitamente planteada por la realidad virtual de producir una experiencia semejante a lo que producen las cosas, el intento definición de lo que es la realidad virtual difícilmente puede escapar a la pregunta por la diferencia entre la experiencia de las cosas y la experiencia de los signos. Si fuéramos capaces de responderla satisfactoriamente, quizás pudiéramos también ser más precisos a la hora de contestar la pregunta por el tipo de efectos que son capaces de producir ese tipo de signos que son las imágenes visuales de la realidad virtual.

\section{LA EXPERIENCIA DE LAS COSAS, LA EXPERIENCIA DE LOS SIGNOS}

En la lucha por la supervivencia, en el esfuerzo continuado por dar sentido al mundo y a las relaciones que mantenemos con los otros, hemos aprendido a contemplar ciertas presencias como cosas, mientras que en otras no vemos más que signos. Para tratar de distinguir una experiencia de otra podríamos escoger casos claros de experiencia de cosas y de signos. El primero nos llevaría a la percepción de un objeto sensible y la descripción de las sensaciones correspondientes; el segundo a la interpretación de un cuadro, un texto literario, un anuncio publicitario, etc. Sin embargo quizá nos sea más útil recurrir aquellos casos en los que el mismo fenómeno puede ser interpretado como cosa y como signo. Resulta asombroso cómo hemos aprendido cambiar el enfoque de nuestra mirada para ver lo que tenemos ante nosotros ahora como un signo, ahora como una cosa; o, a la inversa, para ver ahora una cosa, ahora un signo. Contemplo un cuadro de uno de esos pintores que, como Barceló, añaden cosas a sus telas pintadas. Mi primera mirada reposa sobre el conjunto de la obra tratando de adoptar esa otra forma de ver que me propone el pintor. En un examen más detenido, me acerco hasta casi tocar la tela y reparo entonces que el pintor ha incluido junto a las capas de pintura, chapas de botellas, no para representar las chapas mismas, sino para darle volumen a su obra. $\mathrm{O}$ unos espaguetis que, contrariamente a lo que podría creerse no se representan a sí mismos. Me separo de nuevo y mi mirada vuelve a ver la obra de arte sin reparar entonces en su materialidad.

Existen otras experiencias más cotidianas. En un centro público busco unos lavabos donde poder asearme. Cuando por fin los encuentro, observo que la puerta que suele estar cerrada ahora está abierta y uno de esos instrumentos que utiliza el personal de limpieza para fregar el suelo está cruzado en la entrada impidiéndome el paso. Podría sin ningún esfuerzo retirar ese obstáculo que me impide penetrar en los servicios. Sin embargo no lo hago porque entiendo que alguien quiere decirme algo: que no pase. En ningún sitio está recogido que tal objeto tenga la función de ser un signo que prohíbe el paso como lo hace la señal viaria redonda, roja con una franja blanca que suele interpretar como "Prohibido el paso". Sin embargo advierto que tiene la misma función. El instrumento de limpieza ya no es una cosa, es un signo que me prohíbe la entrada y al que obedezco sin resistirme. 
La educación de la mirada para ver unas veces cosas y otras veces signos es una de las consecuencias de un aprendizaje que tiene un contexto más amplio: el de las prácticas sociales que dan sentido al mundo, un baúl contenedor de realidades muy diversas. Es en el contexto de esas prácticas en el que no sólo puedo aprender lo que son signos y lo que son cosas sino cómo las cosas se convierten en signos. Esas prácticas presuponen la existencia de reglas que es necesario conocer porque se aplican de forma bastante generalizada, pero también la existencia de situaciones en las que se admite la creación y la innovación.

Como decíamos más arriba, en los últimos tiempos, la reflexión acerca de la importancia cultural de lo simbólico ha insistido tanto en que no puedo acercarme al mundo sino es a través de las representaciones (afirmación que es desde luego correcta), que se dado lugar a una conclusión errónea: que toda experiencia no es otra cosa que interpretación y discurso.

En contraposición, no deja de ser curioso que hayan sido precisamente los poetas los que más han reflexionado sobre el mundo de las cosas. En un texto en el que Octavio Paz comenta la experiencia estética de unos de los heterónimos de Pessoa, Alberto Caeiro, una especie de nuevo Adán, que no se propone nombrar las cosas, ni establecer relaciones entre ellas, nos dice:

No sería difícil demostrarle a Caeiro que la realidad nunca está a la mano y que debemos conquistarla (aun a riesgo de que en el acto de la conquista se nos evapore o se nos convierta en otra cosa: idea, utensilio). El poeta inocente es un mito pero es un mito que funda a la poesía. El poeta real sabe que las palabras y las cosas no son lo mismo y por eso, para restablecer una precaria unidad entre el hombre y el mundo, nombra las cosas con imágenes, ritmos, símbolos y comparaciones. Las palabras no son las cosas: son los puentes que tendemos entre ellas y nosotros. El poeta es la conciencia de las palabras, es decir, la nostalgia de la realidad real de las cosas. Cierto, las palabras también fueron cosas antes de ser nombres de cosas. Lo fueron en el mito del poeta inocente, esto es, antes del lenguaje. Las opacas palabras del poeta real evocan el habla de antes del lenguaje, el entrevisto acuerdo paradisiaco. Habla inocente: silencio en el que nada se dice porque todo está dicho, todo está diciéndose. El lenguaje del poeta se alimenta de ese silencio que es habla inocente. Pessoa, poeta real y hombre escéptico, necesitaba inventar a un poeta inocente para justificar su propia poesía. (1991: 103).

En este breve texto, Octavio Paz da su respuesta, que nosotros compartimos en gran medida, al problema de la experiencia. Esa experiencia muda, anterior al lenguaje mismo que pretendía Agamben, nunca ha sido posible aunque, por otra parte, nos sea necesaria como mito fundante de la experiencia. Gracias al mito del poeta inocente, dice Paz, existe la poesía. Gracias al mito de esa experiencia pura, inocente, existe la experiencia contaminada, impura, que es aquella que llegamos a poseer. En ambos casos estamos ante una conciencia de las palabras (de las representaciones) embargada por la nostalgia de la "realidad real de las cosas". La experiencia es lenguaje, construcción simbólica, pero también apertura a lo otro, a aquello que se nos opone, que nos supera y, en no pocas ocasiones, nos aterroriza porque ni nos pertenece ni está dispuesto a obedecernos. Es la apertura a lo otro, a lo que no es len- 
guaje, lo que hace de la experiencia una aventura peligrosa pero sin la que ninguna novedad sería posible.

La mirada ante las cosas y la mirada ante los signos son miradas muy diferentes. Piénsese en la mirada de Paul Cézanne a la búsqueda de una expresión que sea capaz de apresar la realidad de una montaña siempre distinta y cambiante. O la de un Monet, obsesionado por los nenúfares del estanque de su jardín. El caso de Monet nos resulta especialmente útil porque su correspondencia (2010) se convierte muchas veces en una reflexión continua sobre el proceso de su enfrentamiento con la realidad. Este enfrentamiento aparece como una lucha ordinariamente titánica, en su obsesión por encontrar las formas expresivas mediante las cuales quiere representarla. La tarea del pintor se convierte entonces en la búsqueda de algo que no se acaba de encontrar. La inefabilidad es para el pintor una experiencia cotidiana: la conciencia de lo que inevitablemente se perderá porque escapa a sus posibilidades de expresión ${ }^{11}$. Frente a la experiencia del hombre cotidiano que se enfrenta a una realidad domesticada por el lenguaje, la realidad se presenta al artista definida por una resistencia indomeñable. La pintura se convierte entonces en un tormento, como dice Monet (2010:123), en una maldición que consiste en la búsqueda angustiosa de algo que jamás se llegará a alcanzar (2010:131) $)^{12}$.

Por oposición a esta experiencia de las cosas, la experiencia de las representaciones a las que da lugar es muy diferente. La mirada atormentada del poeta o del pintor contrasta frecuentemente con el que contempla la obra realizada. El espectador que deambula por las salas de un museo y contempla las famosas pinturas de Cézanne o Monet busca en ellas la realidad que las originó y las emociones a las que dio lugar. La primera de estas miradas se detiene ante una especie de muro que la cierra el paso y la obliga a reparar en lo que tiene presente para buscar después un lenguaje que dé sentido y sea capaz de comunicar lo que ve. La segunda es una mirada redirigida, rebotada hacia una ausencia por una forma expresiva. Ante los signos, la mirada está obligada a trascender, a ir más allá, a la búsqueda de otros signos y otras cosas.

Sin que supusieran la extinción de antiguas modalidades de la experiencia, la invención de la fotografía, el cine y la televisión, supuso la aparición de otras formas de experiencia, tanto de las cosas como de las representaciones a que daban lugar. La realidad seguía presentando sus resistencias, pero el lenguaje para hacerse con ella venía en gran medida determinado por el mecanismo utilizado para producirlo. No acabó con la mirada del artista, a la búsqueda siempre de dar su propia versión de aquello que se presenta ante sí; pero la determinó de una forma antes desconocida. El mecanismo acabó sin embargo, con bien lo viera Benjamin, con el aura

11 En este mismo sentido se expresa el pintor español Antonio López, en ese experimento fílmico que intentó llevar a cabo Víctor Erice en El sol del membrillo (1992). Más allá de que el film no sea sino la historia de un fracaso, el pintor reconoce expresamente ante uno de sus visitantes las limitaciones de la pintura para representar una realidad siempre cambiante e inasible.

12 Con la breve descripción de la experiencia del poeta o del pintor no pretendemos extraer conclusiones aplicables a toda experiencia estética; ni siquiera una descripción generalizable del modo en que construimos la experiencia de las cosas. Queremos sólo poner de manifiesto la diferencia entre la experiencia de las cosas y la experiencia de los signos que la peculiar mirada del artista no hace más que evidenciar. 
de la obra única: la obra de arte sometida a su reproducción se convertía en objeto de consumo masivo. La realidad por ella representada, parecía más cercana pero, el signo que la representaba no por ello dejaba de esconder entre sus pliegues la misma resistencia. No hay más que pensar en las realistas fotografías con las que un adolescente decora las paredes de su cuarto para darse cuenta de que los signos no han dejado de cumplir su papel vicario y que su objeto resulta tan lejano como antes. El signo es la manifestación de una insatisfacción, de una ausencia irremediable. La experiencia de los signos no ha logrado colmar el deseo de una realidad que, a pesar de todo, está cada vez más lejana.

La aparición de la imagen digital que han hecho posible las nuevas tecnologías, de las que se nutre la realidad virtual, ha dado lugar a nuevas prácticas sociales. ¿Qué tipo de experiencia podemos esperar de estos nuevos intentos de simulación?

\section{REALIDAD VIRTUAL Y EFECTOS DE SENTIDO}

Para contestar a esta pregunta, no debiéramos olvidar que, como ocurre con cualquier otro tipo de representación, lo que define la realidad virtual, no es sólo la naturaleza de la representación (las imágenes móviles digitalizadas), ni tampoco el tipo de objeto representado, ni siquiera, el modo de la representación, sino el conjunto de todo ello, que es lo que da lugar a determinados efectos de sentido. Habrá que preguntarse, pues, por los efectos de sentido, es decir, por el tipo de experiencia que es capaz de producir en relación con los otros tipos de imágenes que el hombre es capaz de producir.

A pesar de lo que a veces se nos quiere hacer $\operatorname{creer}^{13}$, la realidad virtual está hoy condicionada por la una realidad tecnológica más bien limitada pero que confía en un desarrollo que le acerque a un mundo ideal de momento inalcanzable. En cuanto ideal, la realidad virtual está alimentada por un imaginario cuya fuente ha sido la ficción literaria y cinematográfica (el ciberespacio del Neuromante de Gibson o el Holodek de Star Trek, por aludir a unos referentes ya tópicos). No puede extrañar que en ciertos momentos se haya convertido, como quiso ver D. Zeltzer (Heim 1993:123), en una especie de Santo Grial que alimenta nuestros sueños. Pero lo cierto es que sus limitaciones siguen siendo básicamente las mismas que las que presentaban la imagen de naturaleza pictórica o fotográfica: la de la representación que se esfuerza en sustituir el mundo de las cosas por un doble. Esta afirmación no contradice algunas evidencias: en el intento de conseguir simulacros más perfectos de las cosas se han logrado conquistas insospechadas.

Cuando en apartados anteriores analizábamos los medios de representación de la realidad virtual veíamos cómo la imagen visual sigue teniendo una preeminencia

13 A este respecto, es in duda llamativo que programas de televisión divulgativos, que tienen un cierto aire de cientificidad porque se basan en entrevistas a científicos y expertos prestigiados en sus respectivos campos, como es Redes (TVE), contribuyan a difundir ideas que no se ajustan a lo que razonablemente puede preverse. Véase como muestra el titulado "Realidad virtual e inteligencia artificial" disponible en http://www.youtube.com/watch? $\mathrm{v}=\mathrm{RoS} 6 b_{s}$ _qMM [consultada 14/05/2011], en el que se entrevista Raymond Kurzweil, presentado como "la persona que mejor predice el futuro". 
indiscutible, por más que no puedan olvidarse las imágenes acústicas (que ya tienen una tradición poderosa tras de sí) y las imágenes hápticas (que son las que resultan más novedosas). Las nuevas imágenes visuales parecen haber conseguido un ideal antiguo: el de la representación de la tridimensionalidad que percibimos en el mundo de las cosas. Para conseguirlo se ha recurrido, en ocasiones de forma conjunta, a nuevas convenciones que afectan a la representación misma de las cosas y del espacio, las formas, los colores, los tamaños, los movimientos, etc., y a nuevas prótesis oculares que hacen posible la visión binocular de imágenes bidimensionales. La situación actual es en algunos aspectos comparable a los de los primeros momentos del cinematógrafo o la de aquellos otros en las que introducen modificaciones tan relevantes como lo fueron el sonido y el color: unos efectos de realidad sorprendentes. El cine y la televisión en 3D, y no sólo la realidad virtual, están empezando a explorar las posibilidades de un consumo masivo de estos hallazgos. Es posible por tanto que se impongan nuevos medios de representación que serán entendidos como más realistas aunque lo que hagan no sea más que otra forma de alimentar la ilusión de realidad.

Si tenemos en cuenta cuáles fueron los ideales de los pioneros de la realidad virtual y cuáles han sido los logros nos encontramos con una realidad ambivalente. El sueño de pasar, como Alicia, al otro lado de la pantalla, e introducirse en los mundos creados por la tecnología, sigue siendo un logro muy limitado. Por el contrario, no cabe duda de que en lo que más se ha avanzado ha sido en la creación de un entorno de interfaz que hace más naturales las comunicaciones con las máquinas. La interacción que demandan los nuevos dispositivos ha variado en cantidad y calidad. Si bien es cierto que la interpretación de textos siempre ha sido ha demandado la actividad, en ocasiones creadora (Castañares 1994), del intérprete, no es menos cierto que las nuevas textualidades de la realidad virtual exigen otro tipo de actividad. Tanto es así que hay que reconocer que las antiguas terminologías de "lector", "espectador", "intérprete", "usuario", etc., ya no nos sirven porque no hacen justicia a lo que designan. Es posible que aún no hayamos encontrado el término adecuado. Se ha propuesto el término "interactor" (Machado 2009: 132), que no es ni original ni especialmente agradable, pero al menos describe mejor a un nuevo sujeto textual que está entre el autor y el destinatario de los antiguos medios. Nunca como ahora se había puesto de manifiesto que, como decía Eco, el texto es un mecanismo perezoso que hay que activar. El motor de la representación no es ya un aparato tecnológico que tiene autonomía (como en el cine), sino que es el interactor con sus acciones el que moviliza al texto. El movimiento depende de aquel que está dispuesto a contemplarlo pero también a activarlo.

Esta nueva actividad está a veces muy vinculada al movimiento y al tacto. La realidad virtual es una imagen en movimiento que también reacciona al movimiento y al tacto del interactor. La ilusión de realidad que producen no debe sin embargo impedir un análisis distanciado de qué tipo de movimiento y qué tipo de tacto demandan y producen. Como decíamos más arriba, uno de los efectos de realidad más logrados es el del movimiento, no el de las imágenes mismas, sino el que las imágenes producen en el espectador: el espectador tiene la impresión de moverse transgrediendo las leyes de la gravedad que rigen en el mundo real. El movimien- 
to en todas direcciones, la lentitud o la velocidad ad libitum, el vértigo, son sensaciones que ningún otro tipo de imágenes habían conseguido hasta el momento. Lo más cercano a estas sensaciones son los efectos de la cámara subjetiva en el cine, que vemos ahora potenciados de nuevo, no por un mecanismo previo, sino por la voluntad omnipotente del espectador. Como ha señalado Manovich (2005: 332), más que el movimiento articulado por los ejes vertical y horizontal que organiza la visión y el movimiento humano, hace un posible un espacio isotrópico que no privilegia ningún eje y para el que no existe gravedad. Este tipo de perspectiva contribuye sin duda a producir el soñado efecto de inmersión o el del vuelo. Al estar inmerso en la representación, el sujeto se sitúa en el punto de vista de un personaje, de un actor situado en el interior del espacio representado que goza, además, de posibilidades de movimiento que no son los de la vida real. Sin embargo esta decisión produce efectos paradójicos: la cámara subjetiva renuncia a la mirada exterior que permite contemplar toda la escena desde distintos puntos de vista. Los efectos narrativos de este procedimiento son conocidos porque la literatura y el cine consideraron que la multiplicación de la mirada del narrador objetivo o del narrador omnisciente eran hallazgos que producían efectos estéticos de una gran riqueza. Pero la mirada subjetiva ancla al sujeto a una acción más bien monótona y empobrecedora. El cine ha sabido utilizar con maestría este procedimiento, pero siempre combinándolo con otros que permitían al espectador adoptar perspectivas más objetivas y omniabarcantes. Como ocurre con el color o el tamaño de los objetos, estas sensaciones, más que reales, son hiperreales.

Los efectos de realidad conseguidos por el tacto están lejos de los producidos por el movimiento. Más que la textura, la humedad y la temperatura, que constituyen sensaciones inmediatas producidas por los objetos del mundo real, lo que está en juego es el gesto, la presión y, en algunos casos como el de los simuladores, la resistencia. No estamos, de momento al menos, ante el tacto de los objetos, sino ante una especie de poder taumatúrgico que actúa sobre las imágenes para aumentarlas o disminuirlas de tamaño, desplazarlas, ocultarlas o hacerlas aparecer.

No nos detenemos aquí en la cuestión de los objetos representados. Ya hemos dicho que, contrariamente a lo que muchas veces se da a entender, el objeto de la realidad virtual pueden ser tanto una realidad existente como un ente de ficción ${ }^{14}$. Nada nuevo sin embargo porque si algo ha mostrado la semiótica, es que ni la naturaleza de la representación ni tampoco el modo de representar determinan la forma de ser del objeto representado. Justamente por eso el mismo tipo de discurso puede servir para mentir y para decir la verdad. Que produzca uno u otro tipo de efecto depende de convenciones, de situaciones comunicativas y de ciertas inclinaciones de los sujetos. Esto lo supieron muy pronto los griegos y por eso inventaron la retórica. La realidad virtual no presenta en este sentido ninguna peculiaridad. Más allá de que dé lugar a una cierta paradoja terminológica, se trata de una consecuencia lógica que se deriva de su naturaleza esencial: el de ser una representación.

14 A pesar de lo que muchas veces se hace, el término virtual no debiera utilizarse para referirse a los entes de ficción. Quienes recurren a ese uso lo único que hacen es sustituir la oposición real/ficción, por real/virtual. Pero, como ya mostrara Deleuze, este planteamiento es equívoco. 
En cambio, las nuevas formas de representación utilizadas en la realidad virtual y el tipo de interacción que demandan sí tienen consecuencia para los modos de la representación. Aunque no podamos decir que hayan sido desarrolladas por la realidad virtual o, incluso, incorporadas a sus manifestaciones, no cabe duda de que están disponibles nuevas formas de narrar, nuevas formas de describir y nuevas formas de producir efectos de verdad. En los textos tradicionales, la organización de la trama era un privilegio del autor. La interacción y la libertad para moverse por el texto que las nuevas tecnologías permiten a sus usuarios, hacen posible que la secuencia de los hechos y el fin de las historias narradas puedan modificarse a voluntad. El interactor puede escoger diversos caminos narrativos. La narración, concebida como el cambio operado en unos personajes que viven peripecias más o menos aventureras, no es sin embargo la única forma de avanzar por los caminos que pueden abrirse en los mundos reales o ficticios recreados por las imágenes de los nuevos medios. A veces se trata simplemente de realizar un recorrido, un viaje, de visitar ciertos lugares, de acceder a mundos organizados en niveles más o menos jerarquizados. De ahí que se hayan resucitado las figuras del flaneur y del aventurero (Manovich 2005: 339 ss.) como tipologías de la exploración que hacen posible los mundos virtuales. La imagen virtual no ha hecho más que profundizar en las posibilidades de descripción que ya poseían las imágenes fotográficas y fílmicas. Las innovaciones permitirán nuevas formas de representación que influyan poderosamente en los modos de la mímesis y, en definitiva, en las posibilidades de decir "esto es aquello". Por último, los efectos de verdad que son capaces de producir darán lugar a procedimientos que pueden ser explorados por una retórica que puede ser revolucionada de forma aún más profunda que la que la imagen produjo en la publicidad y en el discurso propagandístico.

Si observamos la situación actual de la realidad virtual se tiene la impresión de que estamos aún en un momento de desarrollo casi embrionario. Los avances en la capacidad de procesamiento de la información permitirán, aparte de integrar avances que de de momento encontramos en otras tecnologías, la introducción de otros nuevos. Todo ello contribuirá a aumentar esos efectos de realidad que no dejarán de perseguirse porque nunca serán suficientes. Por su parte, la realidad virtual contribuirá de modo decisivo a profundizar en los cambios de experiencia que ya se están realizando. De hecho, podemos apreciar modificaciones sustantivas en las formas de producir, transmitir, distribuir y procesar la información. Lo mismo puede decirse de los efectos que se están produciendo en la conformación de un imaginario que no sólo está reformulando las representaciones, las evidencias, los valores y los presupuestos normativos heredados, sino que están introduciendo nuevos contenidos que conformarán la forma en que los sujetos se conciben a sí mismos, al mundo, a los otros y a los modos de relacionarse con ambos.

\section{CONCLUSIONES}

Entendida como aquí lo hemos hecho, la realidad virtual aparece como una forma de representación cuyo objetivo fundamental en la reproducción y creación de 
mundos que puedan ser percibidos como lo es el mundo físico de la vida cotidiana. Esta visión nos ha llevado a concebirla de forma muy semejante a los simulacros. Sin embargo, una descripción detenida obliga a introducir matices en estas consideraciones. Si subrayamos que los simulacros son una de las modalidades del fingir, como hace Baudrillard, no cabe duda de que la realidad virtual presenta elementos que no se ajustan, ni pueden pretender ajustarse, a esa intencionalidad. Si el engaño presupone la ignorancia de aquel al que está dirigido, que es lo que permite la sustitución de algo por algo, la realidad virtual no puede aspirar a ese tipo de engaño. Lo más que se podría decir es que estamos ante una operación de sustitución consentida. En otros términos, o no hay fingimiento o el fingimiento es, a su vez, un fingimiento, un simulacro. La razón parece clara. Antes de la aparición de las representaciones digitalizadas, los simulacros estaban construidos con una materia muy semejante a aquella de la que están hechos los objetos representados o, cuando se trataba de acciones, de comportamientos muy similares a aquellos que se llevan a cabo en las situaciones reales. La realidad virtual no está hecha de esa materia y los comportamientos que exige sólo en alguna medida son similares. Examinados de cerca, los procedimientos de los que se vale para producir efectos de realidad en ocasiones se aproximan bastante a los que producen los estímulos de las cosas reales, pero en cambio, en otras, no tiene más remedio que acudir a convenciones más o menos alejadas de lo real, como han hecho sus antecesores en esa escalada que iniciara el hombre hace ya miles de años y cuya pretensión es sustituir la realidad por sus representaciones. Se ha especulado en ocasiones con la posibilidad de que la experiencia de la realidad virtual fuera indistinguible de la experiencia de las cosas. Lo hemos visto también con una cierta frecuencia en las narraciones de la ficción cinematográfica. Pero lo cierto es que, en el contexto de la tecnología actual, tal indiferenciación no parece posible. Cualquiera que haya hecho uso de la tecnología de la realidad virtual sabe que un engaño de esa naturaleza es impensable. Hemos mostrado que la experiencia de la realidad y la experiencia de las imágenes (signos) son muy diferentes. La experiencia de la realidad nos remite a algo que se resiste a nuestra pretensión de dominarlo con nuestras representaciones; la experiencia de las imágenes nos pone ante entidades que, más que resistirse, actúan de puente o trampolín que nos reenvían a algo que está más allá de ellas. La experiencia de las representaciones remitirá siempre a algo que es percibido como una ausencia. Pero si no consigue dar satisfacción al antiguo deseo de sustituir las cosas o la personas por sus representaciones, la realidad virtual está contribuyendo de forma decisiva en la conformación de imaginarios que están introduciendo nuevas formas de conocer y relacionarse con el mundo, con los otros y con nosotros mismos. Es por este camino por donde es posible realizar aún un largo recorrido. 


\section{REFERENCIAS BIBLIOGRÁFICAS}

ABRIL, G. (2007). Análisis crítico de textos visuales. Mirar lo que nos mira. Madrid: Síntesis. Agamben, G. (2001). Infancia e historia. La destrucción de la experiencia y el origen de la historia. Buenos Aires: Adriana Hidalgo.

BAUdRILlaRD, J. (1984). Cultura y simulacro. Barcelona: Kairós.

BAzIN, A. 1999. ”Ontología de la imagen fotográfica”. En A. Bazin, ¿Qué es el cine? Madrid: Rialp, pp. 23-30.

Benjamin, W.(1982). "La obra de arte en la época de su reproducibilidad técnica". En W. Benjamin, Discursos interrumpidos. Madrid: Taurus, pp. 17-57.

(1991). "Sobre el programa de filosofía venidera". En W. Benjamin Para una crítica de la violencia y otros ensayos. Iluminaciones $I V$. Madrid: Taurus, pp. 75-84.

BioscA, A. (2009) "Mil años de virtualidad: origen y evolución de un concepto contemporáneo", Eikasía. Revista de Filosofía V, 28. <http:/www.revistadefilosofia.com/> [Consultada 16-05-2011]

BREA, J.L. (2010). Las tres eras de la imagen. Imagen-materia, film, e-image. Madrid: Akal.

CASTATAÑARES, W. (1994). De la interpretación a la lectura. Madrid: Iberediciones. [Edición electrónica, Madrid: Fragua, 2010]

(2007). "Cultura visual y crisis de la experiencia". CIC 12: 29-48.

(2010). "El uso de la fotografía en la autorrepresentación de los sujetos en las redes sociales”. En M. Torregrosa (coord.), Imaginar la realidad. Ensayos sobre la representación de la realidad en el cine, la televisión y los nuevos medios. Sevilla: Comunicación Social

Deleuze, G. (1984). La imagen-movimiento. Estudios sobre cine 1. Barcelona: Paidós (1987). La imagen- tiempo. Estudios sobre cine 2. Barcelona: Paidós (2002). Diferencia y repetición. Buenos Aires: Amorrortu

HeIm, M. (1993). The metaphisics of virtual reality. New York: Oxford University Press

HidAlgo, A. (2009). "Realidad y mundo. ¿Es cuestionable la 'realidad' del mundo?” Eikasia. Revista de Filosofia, IV, 24. <http://www.revistadefilosofia.com/> [Consultada 16-052011]

JAY, M. (2003). La crisis de la experiencia en la era postsubjetiva. Santiago de Chile: Universidad Diego Portales.

Krueger, M. W. (1983). Artificial Reality. Reading (Mass): Addison-Wesley.

LANIER, J. (1988). "Real virtuality (Interwieu)". Whole Earth Review. <http://www.jaronlanier.com/vrint.html> (Consultada 17-05-2011)

LÉvy, P. (1999). ¿Qué es lo virtual? Barcelona: Paidós.

Machado, A. (2009). El sujeto en la pantalla. La aventura del espectador, del deseo a la acción. Barcelona: Gedisa.

Manovich, L. (2005) El lenguaje de los nuevos medios de comunicación. Barcelona: Paidós.

Monet, C. (2010). Los años de Giverny. Correspondencia. Madrid: Turner.

Paz, O. (1991). "El desconocido de sí mismo". En O. Paz, Cuadrivio. Barcelona: Seix Barral.

PÉrez Herranz, F.M. 2009 "Realidad virtual y materialidad”, Eikasia. Revista de Filosofia, IV:24 . <http://www.revistadefilosofia.com/> [Consultada 16-05-2011]

SchaefFer, J. M. (2002). ¿Por qué la ficción? Madrid: Lengua de trapo.

WALKER, J. (1988). "Through the Looking Glass". <http://www.fourmilab.ch/autofile/ www/chapter2_69.html> (Consultada 17-05-2011). 


\title{
RESUMEN
}

Este artículo adopta una perspectiva de la realidad virtual que descentra la reflexión filosófica para mostrar que se trata, más que de un problema ontológico (virtual versus real; virtual versus actual) de un problema semiótico. La realidad virtual es una imagen de naturaleza visual, sonora y háptica que tiene una vocación: ser el simulacro perfecto, pasar por aquello que representa. Sin embargo el tipo de experiencia que produce no es una experiencia de cosas, sino una experiencia de signos. Como sus antecesoras, la imagen fotográfica y fílmica, produce efectos de realidad recurriendo a convenciones eficaces que contrastan con las que hasta ahora se han utilizado. Pero aunque no consigue totalmente los fines que se proponen, estos efectos de realidad dan lugar a experiencias que están modificando de forma significativa el imaginario del hombre del siglo XXI.

Palabras clave: Realidad virtual, semiótica, experiencia, mímesis, simulación, imaginario.

\begin{abstract}
This article shows a perspective of virtual reality that goes beyond the philosophical reflection to advance in the matter not considering it as an ontological one, but as a semiotical issue. Virtual reality is a visual, accoustic and haptic image with one scope: to be the perfect simulacrum, to substitute what it represents. But the type of experience that virtual reality produces is not an objects' experience, but a signs' one. As its precedents, the photographic and the film image, it produces reality effects using effective conventions which are in contrast with the ones used until now. Even if it does not achieve the goal towards which they are proposed, these reality effects produce experiences that are modifying significantly the man's imaginary of XXIth. Century.
\end{abstract}

Key Words: Virtual reality, semiotics, experience, mimesis, simulation, imaginary.

\section{RÉSUMÉE}

Cet article adopte un point de vue sur la realité virtuelle que décentre la reflexión philosophique et considère la question en tant que semiotique, et pas ontologique. La réalité virtuelle est una image visuelle, accoustique et haptique avec un unique but: celui de passer par celà que elle représente. Le type d'expèrience que la réalité virtuelle produit n'est pas une expérience des objects, mais une expérience des signes. Comme leur précedents, l'image fotographique et l' image du film, elle produit des effects de realité en utilisant des conventions efficaces très divers à les utilisées jusqu'à ce moment. Mème si elle ne parvient pas au but auquel elle s'est proposée, ces effects de realité causent des expèriences que son en train de modifier significativement l'imaginaire de l'homme du XXIème siècle.

Mots clé: Realité vituelle, semiotique, expérience, mimesis, simulacion, imaginaire. 